\title{
Kajian Normalisasi Terhadap Kapasitas Sungai Gude Desa Pulolor Berbasis HEC-RAS
}

\author{
Armanda Beta Saputra ${ }^{1}$, Danayanti Azmi Dewi Nusantara ${ }^{2}$ \\ ${ }^{12}$ ProgramTeknik Sipil, Fakultas Teknik, Universitas Negeri Surabaya \\ Email: ${ }^{1}$ armandasaputra16050724036@mhs.unesa.ac.id, ${ }^{2}$ danayantinusantara@unesa.ac.id
}

\begin{abstract}
Floods that occur due to the overflowing of Gude River are the main problem in Jombang Regency. Gude River is a river with a length of $8.67 \mathrm{~km}$ that flows from Gudo sub-district behind the Sengfong company which is split into the Gude Denanyar River and the Gude Ploso River. This study discusses the normalization of Gude River capacity at a 20 year return period using HECRAS software. In this study, the method used to calculate the design flood is Nakayasu unit synthetic hydrograph and the HEC-RAS software for flow simulation modeling. The calculation result of the flood discharge with a return period of 2 years is $76,89 \mathrm{~m} 3 / \mathrm{sec}$, at 5 years it is $91,59 \mathrm{~m} 3 / \mathrm{sec}$, at 25 years it is 113,62 m3/sec, at 50 years it is $122,75 \mathrm{~m} 3 / \mathrm{sec}$, and at 100 years is $131,80 \mathrm{~m} 3 / \mathrm{sec}$. Based on the discharge data and topographical data of Gude River that has been inputted at the HECRAS, it shows that the overflow occurs in almost all river cross sections except at Sta 0, Sta 14, and Sta 17. Normalization can be carried out to overcome the overflow of Gude River, by dredging sedimentation as deep as 1,5 meters and constructing embankments on both sides of the river with a height of 1.3 meters.
\end{abstract}

Keywords: Discharge, Flood, HEC-RAS, Nakayasu, River.

\begin{abstract}
Abstrak
Banjir yang terjadi karena meluapnya Sungai Gude merupakan permasalahan utama Kabupaten Jombang. Sungai Gude merupakan sungai dengan panjang 8,67 km yang mengalir dari kecamatan Gude melewati belakang PT. Sengfong yang terpecah menjadi Sungai Gude Denanyar dan Sungai Gude Ploso. Penelitian ini membahas tentang kapasitas Sungai Gude terhadap beberapa debit banjir rencana. Metode yang digunakan untuk menghitung debit banjir rencana yaitu hidrograf satuan sintetik nakayasu dan software HEC-RAS untuk pemodelan simulasi aliran. Hasil perhitungan debit banjir dengan periode ulang 2 tahun adalah $76.89 \mathrm{~m}^{3} /$ detik, pada 5 tahun adalah $91,59 \mathrm{~m}^{3} /$ detik, pada 25 tahun adalah $113,62 \mathrm{~m}^{3} /$ detik, pada 50 tahun adalah $122,75 \mathrm{~m}^{3} / \mathrm{detik}$, dan pada 100 tahun adalah $131,80 \mathrm{~m}^{3} /$ detik. Hasil simulasi banjir berdasarkan debit periode ulang, menunjukkan terjadinya luapan hampir di seluruh penampang kecuali pada Sta 0, Sta 14, dan Sta 17. Untuk mengatasi luapan Sungai Gude dilakukan normalisasi dengan cara dilakukan pengerukan sedalam 1,5 meter dari kondisi eksisting dan pembangunan tanggul di kedua sisi sungai dengan ketinggian 1.3 meter.
\end{abstract}

Kata Kunci: Banjir, Debit, HEC-RAS, Nakayasu, Sungai.

\section{Pendahuluan}

Banjir merupakan bencana alam yang diakibatkan oleh sungai tidak mampu menampung tingginya intensitas hujan yang terjadi, banjir dapat terjadi kapanpun dan di manapun. Resiko terjadinya banjir disebabkan karena pada akhir-akhir ini terdapat perubahan tata guna lahan yang memicu adanya sedimentasi pada penampang dasar sungai [1].

Dalam sejarahnya, cara menanggulangi banjir dilakukan dengan membangun tanggul dan bendungan, namun cara ini kurang efisien dalam mengendalikan banjir. Salah satu cara yang dianggap mampu mengatasi banjir yaitu dengan normalisasi. Normalisasi adalah sarana mengembalikan fungsi sungai dari pendangkalan atau penyempitan permukaan dasar sungai [2].

Berdasarkan LKPLHD (Lingkungan Kinerja Pengelolaan Lingkungan Hidup Daerah) Kabupaten Jombang Tahun 2016, banjir merupakan permasalahan utama Kabupaten Jombang. 
Berdasarkan LKPLHD disebutkan dari 306 kelurahan, 132 kelurahan terdampak banjir, 20 kelurahan terdampak tanah longsor, 55 kelurahan terdampak puting beliung, dan 22 kelurahan terdampak kekeringan [3]. Berdasarkan kondisi topografinya, Kabupaten Jombang termasuk landai karena memiliki kemiringan 0-2\% dan kapasitas pengaliran yang kurang memadai menjadi faktor penyebab banjir. Kabupaten Jombang berada di ketinggian 44 mdpl yang jelas lebih rendah dari dataran sekitarnya. Karena kebiasaan masyarakat yang buruk untuk membuang sampah di sungai dan dengan adanya bangunan liar di bantaran sungai juga merupakan faktor penyebab terjadinya banjir. Terlebih lagi akibat pengerasan jalan-jalan kampung, ini menyebabkan aliran air pada permukaan sulit untuk meresap kedalam tanah [4].

Kabupaten Jombang memiliki banyak saluran primer dan salah satunya Sungai Gude. Sungai Gude merupakan sungai primer dengan panjang 8,67 km dan luas Daerah Aliran Sungai (DAS) $22 \mathrm{~km}^{2}$ yang mengalir dari kecamatan Gude melewati belakang PT. Sengfong yang nantinya akan terpecah menjadi sungai sekunder yaitu Sungai Gude Denanyar dan Sungai Gude Ploso.

Sungai Gude yang membelah Desa Pulolor sering meluap sehingga beberapa desa di sekitar tergenangi seperti Desa Denanyar dan Desa Pulolor khususnya Dusun Pulo Gentengan. Sungai Gude tidak bisa menampung debit air hujan yang turun ditambah banjir kiriman dari Kecamatan Gude. Akibatnya sebagian rumah di kedua desa terendam banjir yang menyebabkan lumpuhnya aktivitas warga sekitar [5].

Penelitian kali ini dilakukan dengan cara perencanaan pada titik - titik yang mengalami banjir dan bagaimana cara mengatasinya dengan tepat, dengan memerlukan pengerukan atau dengan membuat tanggul untuk mencegah terjadinya limpasan air. Penelitian ini bertujuan untuk menentukan kapasitas tampung eksisting dari Sungai Gude pada kala ulang 2 hingga 100 tahun, jika debit banjir melebihi kapasitas tampung maka diperlukan normalisasi sungai Gude untuk menanggulangi banjir.

\section{Metode}

Data yang akan digunakan pada penelitian ini dibagi menjadi dua jenis yaitu, data primer dan data sekunder. Jenis data primer diperoleh dari penelusuran dan pengukuran dimensi saluran sungai Gude secara langsung (walk trought). Penelusuran ini digunakan untuk mendapatkan gambaran kondisi lapangan dari lokasi penelitian. Pengukuran dimensi sungai dilakukan secara manual menggunakan roll meter ketika kondisi muka air sungai pada titik terendahnya. Data sekunder diperoleh dari Dinas PU Sumber Daya Air Jawa Timur berupa data curah hujan, serta peta topografi DAS Sungai Gude yang diperoleh dari BPBD (Badan Penanggulangan Bencana Daerah) Kota Jombang.

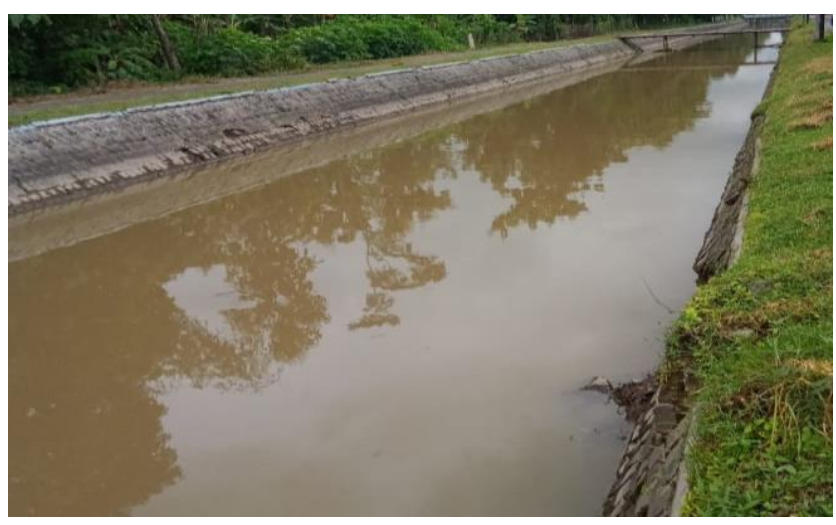

Gambar 1. Penampang Sungai Gude

Gambar 1 memperlihatkan kondisi penampang existing Sungai Gude pada Sta 5 dengan jarak 2125 meter dari Sta 0 (hilir sungai). Berdasarkan pengukuran langsung pada Sta 5 tercatat bentuk penampang sungai adalah trapesium dengan bantaran yang terbuat dari pasangan batu belah dan kemiringan talud 0,457. Ukuran lebar dasar sungai 10,1 meter dengan kedalaman 2 meter. 
Pada Tabel 1 ditunjukkan lokasi stasiun pos hujan yang ditinjau beserta elevasinya. Wilayah DAS Sungai Gude berada diposisi antara ketiga stasiun pos hujan yaitu stasiun pos hujan Ceweng, stasiun pos hujan Tanggungan dan stasiun pos hujan Jombang.

Tabel 1. Lokasi Stasiun Pos Curah Hujan

\begin{tabular}{cccc}
\hline \multirow{2}{*}{ Nama Stasiun } & \multicolumn{3}{c}{ Lokasi } \\
\cline { 2 - 4 } & Lintang Selatan & Bujur Timur & Elevasi (m dpl) \\
\hline Ceweng & -7.592409 & 112.235 & 68 \\
\hline Tanggungan & -7.592765 & 112.184 & 67 \\
\hline Jombang & $-7,509364$ & 112,221 & 43 \\
\hline
\end{tabular}

\subsection{Analisis Hidrologi}

Analisis hidrologi dilakukan untuk memperoleh debit banjir rencana. Berdasarkan data curah hujan yang telah diperoleh, curah hujan pada Das Gude dapat dianalisis menggunakan metode polygon thiessen. Polygon thiessen adalah luas poligon yang telah diukur dikalikan dengan kedalaman curah hujan di stasiun yang berada di dalam poligon [6].

$$
R=\sum_{i}^{n} \frac{A_{n} \times R n}{A n}
$$

dimana: $\mathrm{R} \quad=$ Curah hujan wilayah

$\mathrm{Rn} \quad=$ Curah hujan di setiap stasiun pos hujan

An $\quad=$ Luas daerah pada tiap stasiun pos hujan

Dari hasil perhitungan curah hujan harian rata-rata maksimum dengan metode polygon thiessen dapat dilakukan perhitungan hujan rancangan kala ulang menggunakan metode distribusi Gumbel dan Pearson III.

Persamaan metode Gumbel [7] adalah:

dimana: Rt $\quad=$ Curah hujan rancangan

$$
R t=\underline{R}+\frac{S}{S n}(Y t-Y n)
$$

$\underline{R} \quad=$ Curah hujan maksimum rata-rata

$\mathrm{S} \quad=$ Standar deviasi

Yt =Reduced variated sebagai fungsi dari periode ulang " $\mathrm{t}$ "

Yn =Reduced mean sebagai fungsi dari banyaknya data " $n$ "

$\mathrm{Sn} \quad=$ Reduced Standar deviasi sebagai fungsi dari banyaknya data " $n$

Persamaan metode pearson tipe III [7] adalah:

dimana: Rt = curah hujan rancangan

$$
R t=\underline{R}+\text { Cs.S }
$$

$\begin{array}{ll}\underline{R} & =\text { Curah hujan maksimum rata-rata } \\ \mathrm{Cs} & =\text { Koefisien Skewness }\end{array}$

$\mathrm{S} \quad=$ Standar deviasi

Dari kedua metode perhitungan curah hujan rancangan kala ulang, diambil nilai yang terbesar karena dalam penentuan debit banjir diperlukan kemungkinan terburuk yaitu debit terbesar. Setelah curah hujan rancangan kala ulang diperoleh, harus dilakukan Uji Kesesuaian Distribusi Frekuensi untuk memeriksa kesesuaian antara hasil pengamatan dengan model distribusi yang diharapkan serta untuk memeriksa kebenaran hipotesis. Metode yang digunakan yaitu metode smirnov-kolmogorov. Jika uji kesesuaian distribusi frekuensi diterima maka hasil curah hujan rancangan periode ulang dapat digunakan untuk menghitung debit banjir rancangan.

Pada perhitungan debit banjir rencana ini, perlu menentukan koefisien limpasan pada DAS Gude terlebih dahulu.. Koefisien limpasan merupakan nisbah antara laju puncak aliran permukaan terhadap intensitas hujan. Faktor yang paling mempengaruhi nilai koefisien limpasan yaitu antara lain intensitas hujan, laju infiltrasi tanah dan tanaman penutup tanah [8].

$$
C=\frac{\sum_{i-1}^{n} A_{n} \times C_{n}}{\sum_{i-1}^{n} A_{n}}
$$

dimana: $\mathrm{C} \quad=$ Koefisien limpasan 
$\mathrm{Cn} \quad=$ Koefisien limpasan setiap penggunaan lahan

An $\quad=$ Luas setiap penggunaan lahan

Berdasarkan SNI 2415 tahun 2016 nilai koefisien pengaliran semakin besar maka kondisi permukaan lahan semakin kasar.

Untuk menghitung debit banjir, dapat digunakan rumus hidrograf satuan sintetik (HSS) nakayasu sebagai berikut [7]:

Pertama, menghitung waktu antara hujan hingga debit puncak banjir $\left(\mathrm{t}_{\mathrm{g}}\right)$

Menghitung waktu puncak $\left(t_{\mathrm{p}}\right)$

$$
t_{g}=0,4+0,058 L
$$

$$
\begin{gathered}
t_{r}=0,75 \times t_{g} \\
t_{p}=t_{g} \times\left(0,8 \times t_{r}\right)
\end{gathered}
$$

Menghitung besarnya $t_{0,3}$

$$
\begin{gathered}
\alpha=2 \text { untuk pengaliran biasa } \\
t_{0,3}=\alpha \times t_{g}
\end{gathered}
$$

Menghitung debit maksimum hidrograf satuan

Menghitung besarnya Base Flow $\left(\mathrm{Q}_{\mathrm{b}}\right)$

$$
Q_{p}=\frac{A \times R_{0} \times C}{3,6\left(0,3 T_{p}+T_{0,3}\right)}
$$

Menghitung lengkung hidrograf

$$
Q_{b}=\left(0,5 \times Q_{p}\right)
$$

Bagian lengkung naik (Qa)

Bagian lengkung turun (Qd1)

$$
\begin{gathered}
0<t<t_{p} \\
Q a=Q_{p} x\left(\frac{t}{t_{p}}\right)^{2,4}
\end{gathered}
$$

Bagian lengkung turun $(\mathrm{Qd} 2)$

$$
\begin{aligned}
& t_{p}<t \leq\left(t_{p}+t_{0,3}\right) \\
& Q d 1=Q_{p} \times 0,3^{\frac{t-t p}{t 0,3}}
\end{aligned}
$$

$$
\left(t_{p}+t_{0,3}\right)<t \leq\left(t_{p}+t_{0,3}+1,5 t_{0,3}\right)
$$

Bagian lengkung turun $(\mathrm{Qd} 3)$

$$
Q d 2=Q_{p} \times 0,3^{\frac{t-t p+0,5 \times t 0,3}{1,5 \times t 0,3}}
$$

$$
\begin{gathered}
t>\left(t_{p}+t_{0,3}+1,5 t_{0,3}\right) \\
Q d 3=Q_{p} \times 0,3 \frac{t-t p+1,5 \times t 0,3}{2 \times t 0,3}
\end{gathered}
$$

Setelah debit banjir metode HSS Nakayasu didapatkan selanjutnya diproses menjadi grafik. Hasil dari perhitungan debit banjir tersebut digunakan sebagai input data pada analisa hidrolika.

\subsection{Analisis Hidrolika}

Analsis hidrolika dilakukan dengan penelusuran aliran untuk memprediksi tingginya muka air pada saluran terbuka pada Sungai Gude. Analisa hidrolika dilakukan dengan menggunakan program bantu HEC RAS berdasarkan debit banjir periode ulang..

Program HEC-RAS merupakan program yang mampu melakukan perhitungan muka air kondisi steady (konstan), perhitungan aliran unsteady (tidak konstan), dan perhitungan angkutan sedimen. Model aliran steady satu dimensi akan digunakan pada penelitian ini. Pada perhitungan profil muka air, HEC-RAS menggunakan prinsip persamaan energi antar dua penampang [4]. 


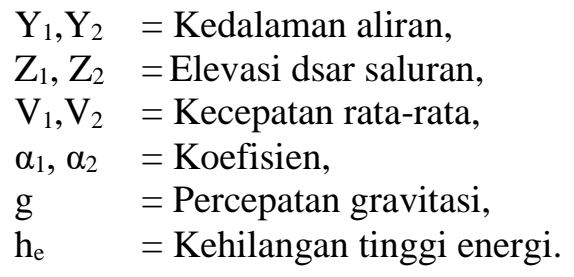

\section{HASIL DAN PEMBAHASAN}

\subsection{Analisis Hidrologi}

Analisis curah hujan wilayah menggunakan metode polygon thiessen didapatkan dari tiga stasiun pos hujan terdekat yaitu stasiun pos hujan Ceweng, stasiun pos hujan Tanggungan, dan stasiun pos hujan Jombang dengan aplikasi Google Earth Pro, sehingga diperoleh hasil seperti Gambar 2.

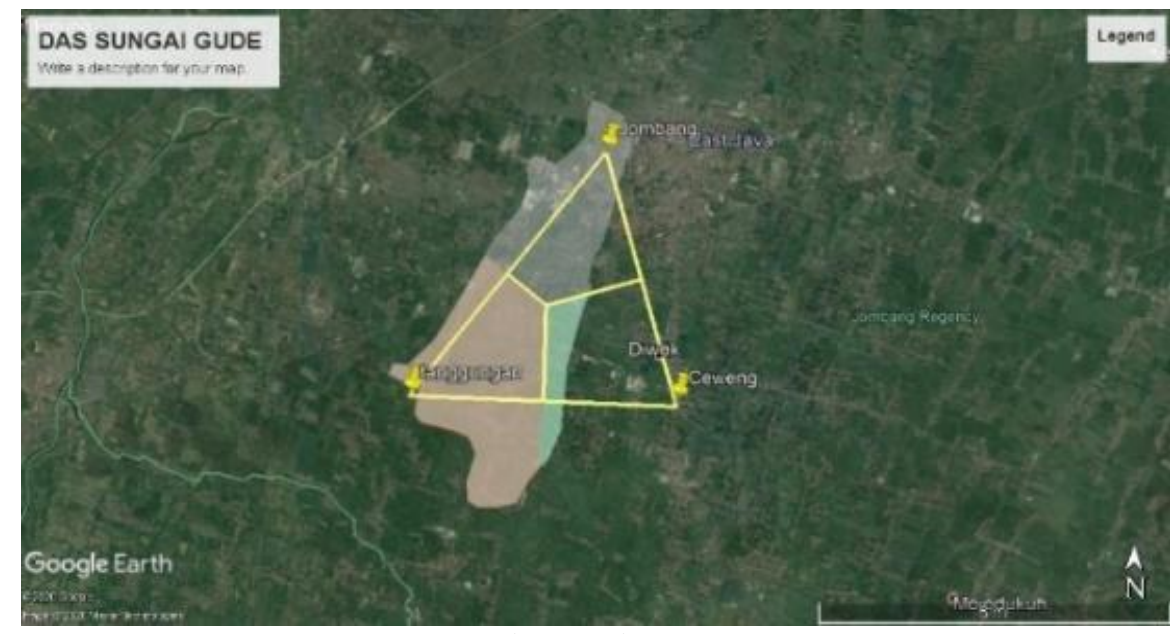

Gambar 2 Polygon Thiessen DAS Gude

Berdasarkan metode polygon thiessen didapat luas daerah pengaruh dari masing-masing pos penakar hujan. yang digunakan untuk menghitung curah hujan wilayah DAS. Berikut merupakan contoh perhitungan curah hujan wilayah berdasarkan metode polygon thiessen, selengkapnya diberikan dalam Tabel 2..

$$
\begin{aligned}
& R_{2004}=\frac{2,15 \times 95+12,00 \times 86+7,85 \times 25}{2,15+12,00+7,85} \\
& R_{2004}=65,11 \mathrm{~mm}
\end{aligned}
$$

\begin{tabular}{|c|c|c|c|c|}
\hline \multirow{2}{*}{$\begin{array}{c}\text { Tahu } \\
\text { n }\end{array}$} & \multicolumn{3}{|c|}{$\begin{array}{c}\text { Curah Hujan Harian } \\
\text { Maksimum (mm) }\end{array}$} & \multirow{2}{*}{$\begin{array}{c}\text { Curah } \\
\text { Hujan } \\
\text { Wilayah }\end{array}$} \\
\hline & $\begin{array}{c}\text { Cewen } \\
\mathrm{g}\end{array}$ & $\begin{array}{c}\text { Tanggung } \\
\text { an }\end{array}$ & $\begin{array}{c}\text { Jomban } \\
\text { g }\end{array}$ & \\
\hline 2000 & 96 & 125 & 62 & 99.69 \\
\hline 2001 & 91 & 85 & 79 & 83.45 \\
\hline 2002 & 88 & 93 & 64 & 82.16 \\
\hline 2003 & 97 & 112 & 42 & 85.56 \\
\hline 2004 & 95 & 86 & 25 & 65.11 \\
\hline 2005 & 92 & 96 & 76 & 88.47 \\
\hline 2006 & 84 & 98 & 107 & 99.84 \\
\hline 2007 & 71 & 90 & 164 & 114.55 \\
\hline 2008 & 112 & 125 & 38 & 92.69 \\
\hline 2009 & 97 & 120 & 130 & 121.32 \\
\hline 2010 & 125 & 113 & 68 & 98.12 \\
\hline
\end{tabular}

Tabel 2 Curah Hujan Harian Wilayah DAS Gude 


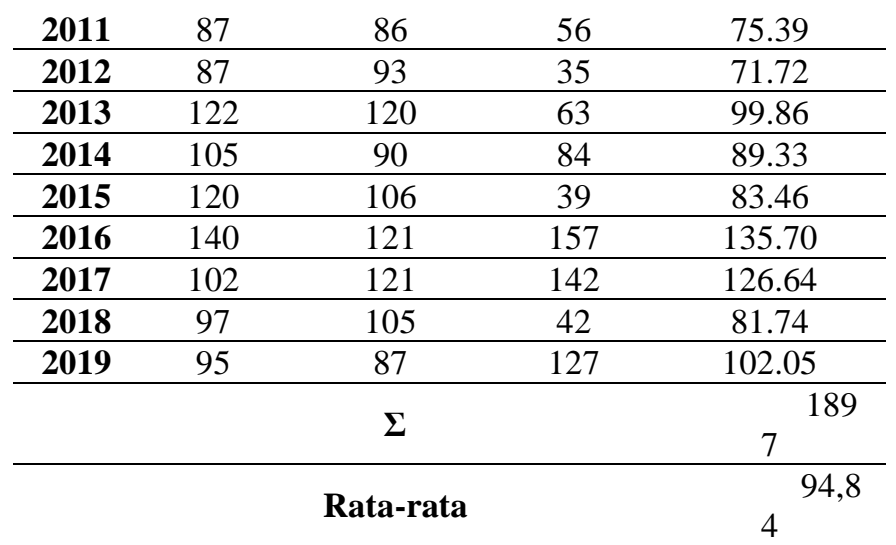

Berikut merupakan contoh perhitungan hujan rencana periode ulang 100 tahun berdasarkan metode Gumbel.

Diketahui :

$$
\begin{aligned}
& \underline{R} \quad=\frac{1897}{19}=94,84 \mathrm{~mm} \\
& \mathrm{~S} \quad=\frac{\sqrt{\sum(R i-\underline{R})^{2}}}{(n-1)}=\frac{\sqrt{6457}}{(20-1)} \quad=18,41
\end{aligned}
$$

Berdasarkan nilai Standar Deviasi yang telah diperoleh, dapat digunakan untuk menentukan nilai dari Reduced Standar Deviasi (Sn) sebesar 1,096 dan Reduced Mean (Yn) sebesar 0,532 dengan mengacu pada tabel Mean dan Standard Deviation untuk Reduced Variate [7]. Dalam menentukan nilai dari Curah Hujan Kala Ulang Metode Gumbel diperlukan Reduced Variate (Ytr) yang mengacu pada tabel Reduced Variate [7]. Gumbel.

Menurut persamaan 2 berikut contoh perhitungan Curah Hujan Kala Ulang 100 Tahun Metode

$$
\begin{aligned}
& R_{100}=94,84+\frac{18,41}{1,096}(4,6-0,532) \\
& R_{100}=168,99
\end{aligned}
$$

Dalam menentukan Curah Hujan Kala Ulang metode Pearson III diperlukan nilai Koefisien Skewness. Berikut hasil perhitungan Koefisien Skewness.

$$
\text { Cs } \quad=\frac{n x \Sigma(R i-\underline{R})^{3}}{(n-1) x(n-2) x\left(S^{3}\right)} \quad=0,68
$$

Nilai dari Koefisien Skewness digunakan untuk menentukan nilai Faktor Frekuensi K (KT) berdasarkan tabel Faktor Frekuensi Koefisien untuk Agihan Pearson III dengan Skewness Positif dan Negatif. Berikut hasil interpolasi nilai Faktor Frekuensi Koefisien pada periode ulang 100 tahun.

$\mathrm{KT}_{100}=2,824$ (didapat dari interpolasi berdasarkan tabel Faktor Frekuensi Koefisien Skewness [7].

Menurut persamaan 3 berikut contoh perhitungan Curah Hujan Kala Ulang 100 Tahun Metode Pearson III.

$$
\begin{aligned}
& R_{100}=94,84+2,824 \times 18,43 \\
& R_{100}=146,901
\end{aligned}
$$

Kedua hasil perhitungan curah hujan rancangan dilakukan rekapitulasi dan ditunjukkan pada Tabel 3. Berdasarkan hasil perbandingan dari kedua metode, diambil nilai curah hujan rancangan tertinggi. Untuk erhitungan selanjutnya yang akan digunakan hasil dari metode Gumbel.

\begin{tabular}{ccc} 
Tabel 3 Perbandingan Curah Hujan Rancangan \\
\hline \multirow{2}{*}{$\begin{array}{c}\text { Period } \\
\text { e }\end{array}$} & $\begin{array}{c}\text { Metode Perhitungan Curah Hujan } \\
\text { Rancangan }\end{array}$ \\
\cline { 2 - 3 } & Gumbel & Pearson III \\
\hline 2 & 97.87 & 92,785 \\
\hline 5 & 116.91 & 109,405 \\
\hline 25 & 145.44 & 131,102 \\
\hline 50 & 157.26 & 139,213 \\
\hline 100 & 168.99 & 146,901 \\
\hline
\end{tabular}


Pengujian parameter dilakukan dengan metode Smirnov-Kolmogorov. Hasil uji kesesuaian distribusi ditampilkan pada tabel 4.

Tabel 4 Perbandingan Hasil Uji Kesesuaian Distribusi

\begin{tabular}{ccc}
\hline Uji Kesesuaian & Nilai Tabel & Nilai Hitung \\
\hline Uji Smirnov - Kolmogorov & 0,29 & 0,1 \\
\hline
\end{tabular}

Dari Tabel 4 dapat dilihat nilai tabel pada kesesuaian distribusi lebih besar daripada nilai hitung. Ini menunjukkan bahwa distribusi yang digunakan sudah tepat.

Untuk menghitung debit banjir rancangan perlu dicari koefisien limpasan dari DAS Gude terlebih dahulu. Koefisien limpasan di sajikan dalam Tabel 5.

Tabel 5 Koefisien Limpasan DAS Gude

\begin{tabular}{lccr}
\hline \multicolumn{1}{c}{ Jenis Lahan } & C & $\begin{array}{c}\text { Luas (A) } \\
(\mathbf{k m 2})\end{array}$ & $\mathbf{A}$ *C \\
\hline Pemukiman & 0,75 & 9,8 & 7,35 \\
\hline Lahan Terbuka & 0,2 & 0,2 & 0,04 \\
\hline Perkebunan & 0,4 & 0,3 & 0,12 \\
\hline Sawah & 0,15 & 11,7 & \multicolumn{2}{c}{1,75} \\
\hline Total & & 22 & \multicolumn{2}{c}{9,26} \\
\end{tabular}

\begin{tabular}{|c|c|c|c|c|c|c|}
\hline \multirow{2}{*}{$\begin{array}{c}\text { Waktu t } \\
\text { (jam) }\end{array}$} & \multirow{2}{*}{$\begin{array}{c}\text { Debit Unit Hidrograf } \\
\left(\mathrm{m}^{3} / \mathrm{s}\right)\end{array}$} & \multicolumn{5}{|c|}{ Total Debit Kala Ulang $\left(\mathrm{m}^{3} / \mathrm{s}\right)$} \\
\hline & & 2 & 5 & 25 & 50 & 100 \\
\hline 0 & 0.000 & 1.33 & 1.33 & 1.33 & 1.33 & 1.33 \\
\hline 1 & 1.329 & 31.39 & 37.24 & 46.01 & 49.64 & 53.24 \\
\hline 1.333 & 2.651 & 76.89 & 91.59 & 113.62 & 122.75 & 131.80 \\
\hline 2 & 1.740 & 58.09 & 69.13 & 85.68 & 92.53 & 99.33 \\
\hline 3 & 0.925 & 34.53 & 40.99 & 50.67 & 54.68 & 58.66 \\
\hline 3 & 0.795 & 32.09 & 38.08 & 47.05 & 50.76 & 54.45 \\
\hline 4 & 0.577 & 25.04 & 29.66 & 36.57 & 39.44 & 42.28 \\
\hline 5 & 0.379 & 16.89 & 19.92 & 24.45 & 26.33 & 28.20 \\
\hline 6 & 0.248 & 11.54 & 13.52 & 16.50 & 17.73 & 18.96 \\
\hline 6 & 0.239 & 11.13 & 13.04 & 15.90 & 17.09 & 18.26 \\
\hline 7 & 0.179 & 8.70 & 10.13 & 12.28 & 13.17 & 14.05 \\
\hline 8 & 0.131 & 6.70 & 7.74 & 9.31 & 9.96 & 10.60 \\
\hline 9 & 0.095 & 5.24 & 6.00 & 7.15 & 7.62 & 8.09 \\
\hline 10 & 0.069 & 4.18 & 4.74 & 5.57 & 5.91 & 6.26 \\
\hline 11 & 0.051 & 3.41 & 3.81 & 4.42 & 4.67 & 4.92 \\
\hline 12 & 0.037 & 2.84 & 3.14 & 3.58 & 3.76 & 3.95 \\
\hline 13 & 0.027 & 2.43 & 2.65 & 2.97 & 3.10 & 3.24 \\
\hline 14 & 0.020 & 2.13 & 2.29 & 2.52 & 2.62 & 2.72 \\
\hline 15 & 0.014 & 1.91 & 2.03 & 2.20 & 2.27 & 2.34 \\
\hline 16 & 0.010 & 1.75 & 1.84 & 1.96 & 2.01 & 2.07 \\
\hline 17 & 0.008 & 1.64 & 1.70 & 1.79 & 1.83 & 1.86 \\
\hline 18 & 0.006 & 1.55 & 1.60 & 1.66 & 1.69 & 1.72 \\
\hline 19 & 0.004 & 1.49 & 1.52 & 1.57 & 1.59 & 1.61 \\
\hline 20 & 0.003 & 1.45 & 1.47 & 1.51 & 1.52 & 1.53 \\
\hline 21 & 0.002 & 1.41 & 1.43 & 1.46 & 1.47 & 1.48 \\
\hline 22 & 0.002 & 1.39 & 1.40 & 1.42 & 1.43 & 1.44 \\
\hline 23 & 0.001 & 1.37 & 1.38 & 1.39 & 1.40 & 1.41 \\
\hline
\end{tabular}




$\begin{array}{lllllll}24 & 0.001 & 1.37 & 1.37 & 1.38 & 1.38 & 1.38\end{array}$

Dari Tabel 5 diolah dengan menggunakan persamaan 4 sehingga diperoleh koefisien limpasan DAS Gude sebagai berikut.

$$
C=\frac{9,265}{22}=0,421
$$

\subsection{Analisis Debit Banjir Metode HSS Nakayasu}

Untuk menentukan nilai debit perlu diperhatikan beberapa parameter sebagai berikut.

Panjang Sungai $(\mathrm{L}) \quad=8670 \mathrm{~m}$

Luas DAS (A) $\quad=22 \mathrm{~km}^{2}$

Elevasi Hulu $\quad=51 \mathrm{mdpl}$

Elevasi Hilir $\quad=44 \mathrm{mdpl}$

Kemiringan Saluran (So) $\quad=0.000807$

Selanjutnya menentukan nilai debit lengkung hidrograf untuk menentukan debit banjir hidrograf dengan menggunakan persamaan 8 sampai persamaan 17. Data yang digunakan yaitu data Curah Hujan Rancangan periode ulang 2, 5, 25, 50, dan 100 tahun dengan metode Gumbel sehingga diperoleh debit banjir rancangan yang disajikan Tabel 6 .

Tabel 6 Perbandingan Debit Banjir Rancangan DAS Gude Metode HSS Nakayasu Sumber: Hasil Perhitungan

\subsection{Analisis Hidrolika}

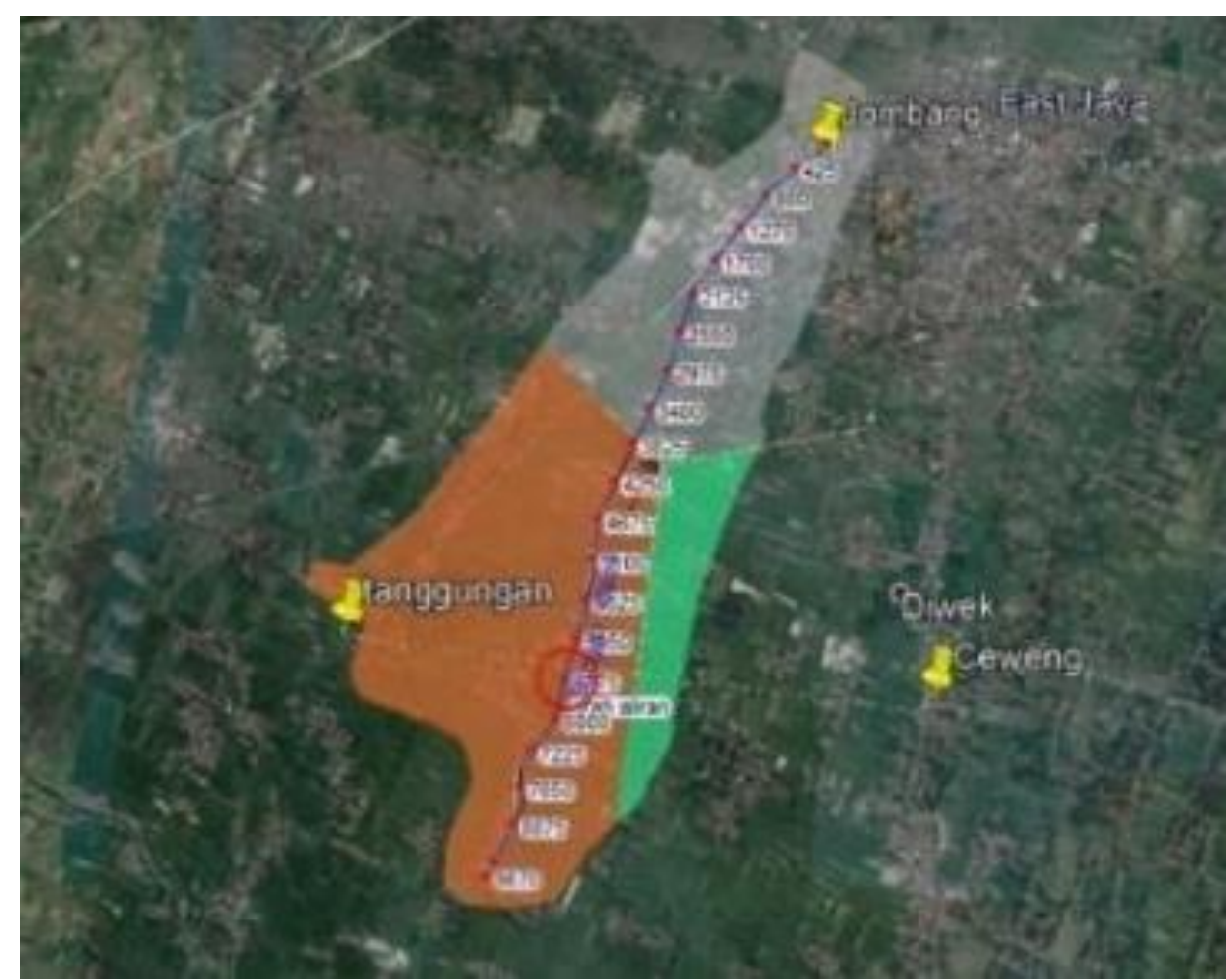

Gambar 3 Pembagian Sta pada Sepanjang Sungai Gude

Simulasi pemodelan aliran digunakan aplikasi HEC-RAS versi 4.1. untuk mengetahui tinggi profil muka penampang melintang dan memanjang Sungai Gude. Dalam penelitian ini aliran Sungai Gude dibagi menjadi 21 section ditunjukkan pada Gambar 3. Stasioning (Sta) 0 merupakan bagian batas hilir Sungai Gude, sedangkan batas bagian hulu sungai ditandai pada Sta 21. Jarak antar Sta terdekat adalah 450 m, kecuali jarak Sta 20 ke Sta 21 memiliki jarak 170 m. Hal ini bertujuan untuk memudahkan dalam pembagian dimensi secara rinci.. 
Berdasarkan data primer yang telah diukur di berbagai Stasioning, terdapat berbagai variasi lebar dan kedalaman sungai. Sebagai contoh pada Sta 5 penampang sungai berbentuk trapesium tanpa tanggul dan permukaan bantaran terbuat dari pasangan batu belah. Sta 5 memiliki lebar dasar saluran 10,1 meter dengan kedalaman dasar sungai 2 meter dan kemiringan talud 0,457. Gambar 4 menunjukkan profil memanjang berdasarkan hasil simulasi HEC RAS untuk beberapa periode ulang.

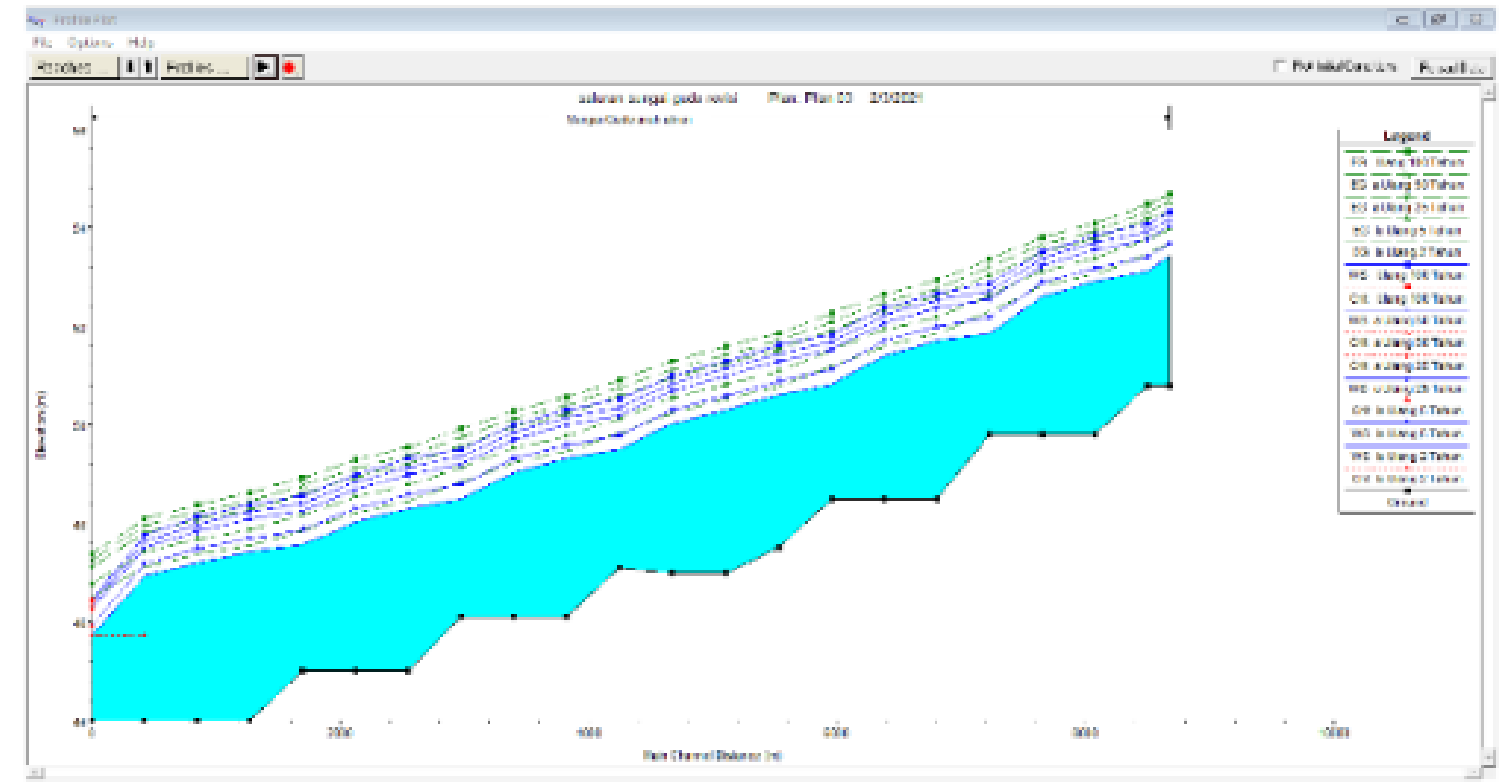

Gambar 4 Plot Profil Memanjang Sungai Gude pada Debit Rencana Periode Ulang 2, 5, 25, 50, dan 100 Tahun

Berdasarkan hasil running aplikasi HEC-RAS dapat diketahui ketinggian air (Water Surface Elevation/WS) di hampir semua titik Stasioning melebihi kedalaman sungai. Hanya pada kala ulang 2 tahun beberapa titik Stasioning tidak melebihi kedalaman sungai. Titik Stasioning tersebut antara lain Sta 0, Sta 14, dan Sta 17. Sedangkan pada kala ulang 5, 25, 50, dan 100 tahun semua ketinggian air melebihi kedalaman sungai. Pada Gambar 5 dapat dilihat profil penampang melintang Sta 5 pada debit rencana kala ulang 2, 5, 25, 50, 100 tahun.

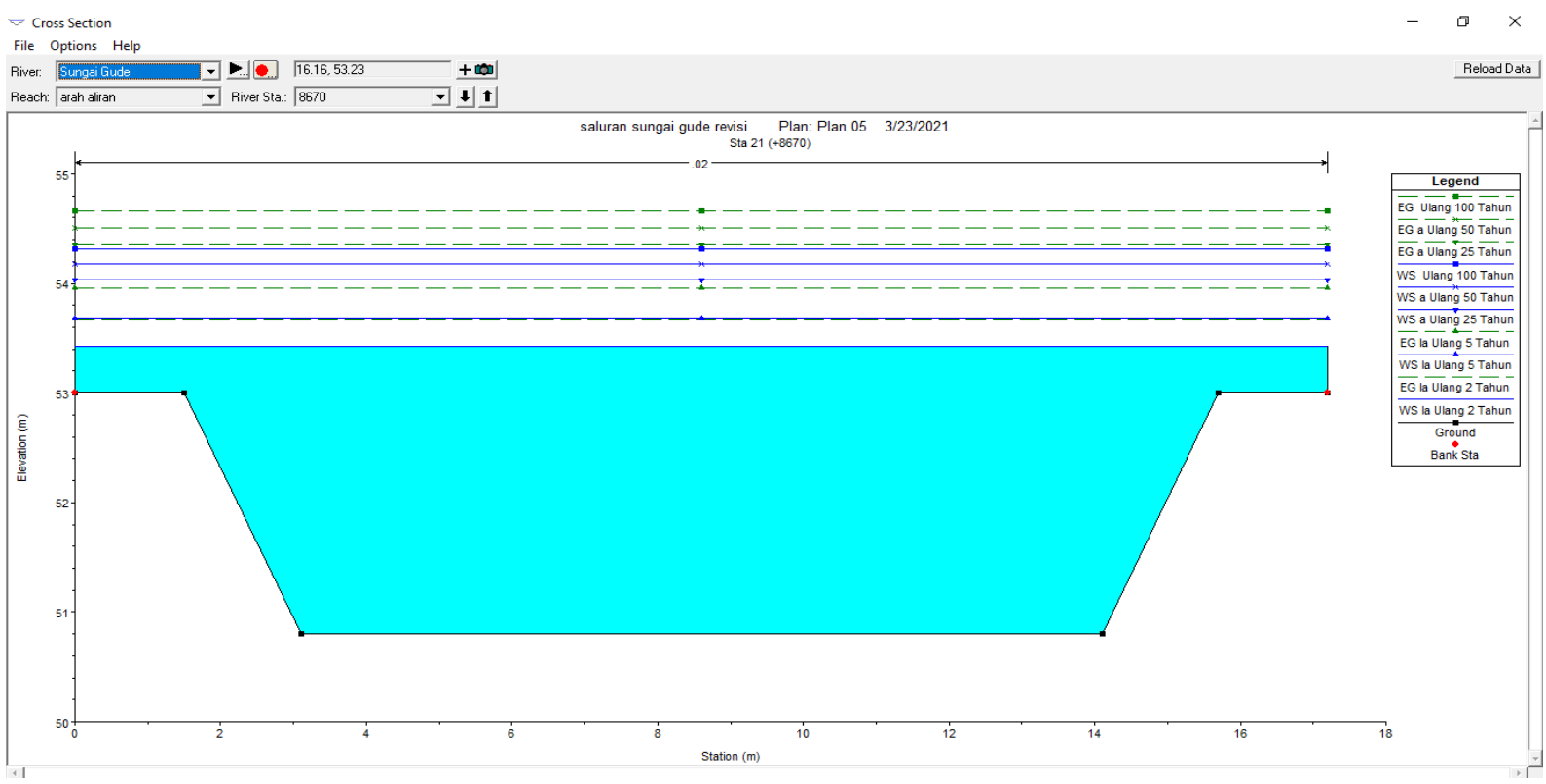

Gambar 5 Plot Profil Melintang pada Debit Rencana Periode Ulang 2, 5, 25, 50, dan 100 Tahun 
Gambar 5 menunjukkan muka air yang meluap di kedua sisi bantaran sungai setinggi 1 meter pada periode ulang 2 tahun, muka air meluap setinggi 1,3 meter pada periode ulang 5 tahun, muka air meluap setinggi 1,7 meter pada periode ulang 25 tahun, muka air meluap setinggi 1,81 meter pada periode ulang 50 tahun, dan muka air meluap setinggi 1,98 meter pada periode ulang 100 tahun. Simulasi hidrolika yang dilakukan dalam penelitian ini merupakan simulasi 1D, bukan 2D maupun 1D2D. Sehingga luapan air yang ditunjukkan dalam potongan profil melintang belum tentu merepresentasikan kedalaman banjir yang terjadi di dataran. Sebab, air yang meluap dari tanggul akan mengalir pada lahan sekitar. Berdasarkan hasil dari running HEC-RAS menunjukkan bahwa di hampir semua penampang sungai tidak dapat menampung debit rencana. Sehingga perlu adanya solusi untuk mengatasi masalah ini dengan cara normalisasi sungai. Normalisasi yang dapat dilakukan yaitu dengan cara mengeruk kedalaman sungai yang terdapat sedimentasi dan dengan pembuatan tanggul di kedua sisi sungai.

\subsection{Redesign Penampang}

Dalam menentukan dimensi dan sempadan sungai perlu dilakukan dengan membuat perkiraan debit banjir rancangan dan elevasi muka air pada debit dominan periode ulang 2 tahun hingga periode ulang 5 tahun (PP Nomor 38, 2011). Bentuk penampang sungai yang digunakan tetap seperti sebelumnya yaitu trapesium karena menyesuaikan kondisi existing. Jika bentuk dari penampang dirubah dapat menyebabkan longsornya tanah pada bantaran sungai, mengingat disekitar bantaran banyak terdapat pemukiman warga sehingga akan banyak beresiko jika penampang dirubah bentuknya.

Diketahui data:

\begin{tabular}{|c|c|c|c|c|c|}
\hline Kemiringan dasar saluran (So) & $=$ & 0,00080 & & & \\
\hline Kedalaman sungai (h) & $=$ & 3,5 & $\mathrm{~m}$ & & \\
\hline Lebar bantaran sungai (b1) & $=$ & 1,6 & $\mathrm{~m}$ & & \\
\hline Lebar sungai (B) & $=$ & 10 & $\mathrm{~m}$ & & \\
\hline Kemiringan bantaran (m) & $\begin{array}{l}= \\
=\end{array}$ & $\begin{array}{l}\mathrm{b} 1 / \mathrm{h} \\
1,6 / 3,5\end{array}$ & & $=$ & 0,45 \\
\hline $\begin{array}{l}\text { Angka manning (n) } \\
\text { (permukaan sungai terbuat dar }\end{array}$ & $=$ & $\begin{array}{l}0,02 \\
\mathrm{hh}\end{array}$ & & & \\
\hline
\end{tabular}

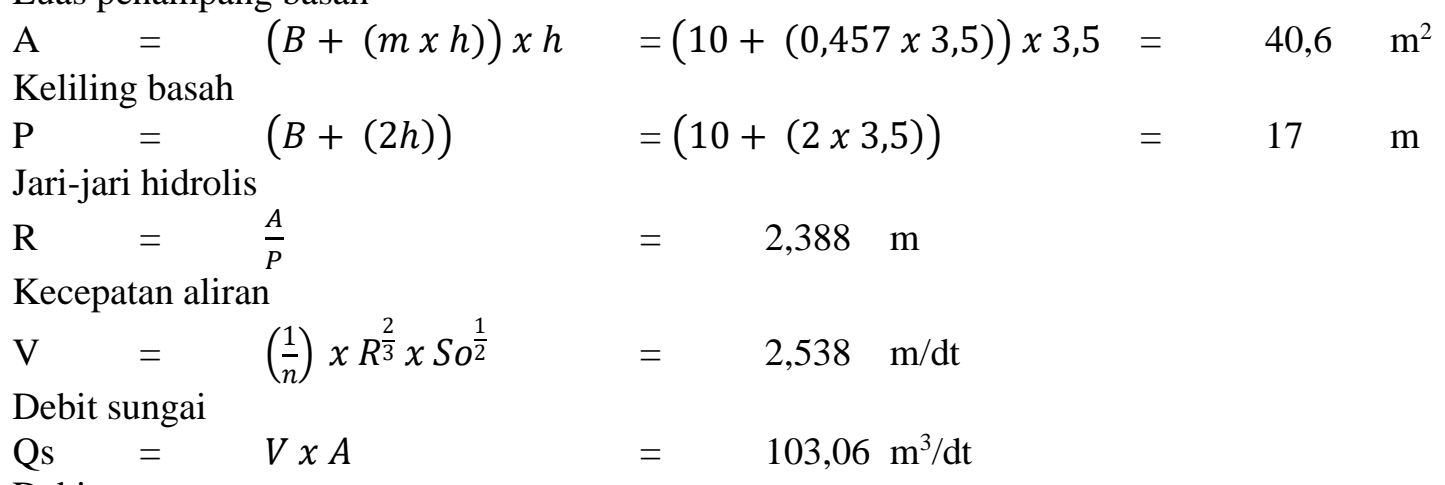

Debit rencana

Qp2 = 76,89 $\mathrm{m}^{3} / \mathrm{dt}$

Qp5 = $91,59 \mathrm{~m}^{3} / \mathrm{dt}$

Kontrol

$\begin{array}{lllll}\text { Qs } & > & \text { Qp5 } & > & \text { Qp2 }\end{array}$

$>\quad 91,59>\quad 76,89$

Tinggi jagaan

Pedoman Perencanaan Drainase, Pd T-02-2006:
$\mathrm{W} \quad=$
$(0,5 \times h)^{\frac{1}{2}}$
$=\quad(0,5 \times 3,5)^{\frac{1}{2}}$
$=$
$1,32 \mathrm{~m}$

Dari hasil perhitungan redesign penampang diketahui penampang sungai berbentuk trapesium dengan lebar dasar saluran 10 meter, kedalaman 3,5 meter, dan kemiringan bantaran 0,457 dapat menampung kapasitas debit rencana periode ulang 2 tahun dan 5 tahun, ini dapat dibuktikan 
berdasarkan perbandingan debit sungai rencana $(\mathrm{Qs})>$ debit rencana 5 tahun $(\mathrm{Qp} 5)>$ debit rencana 2 tahun (Qp2).

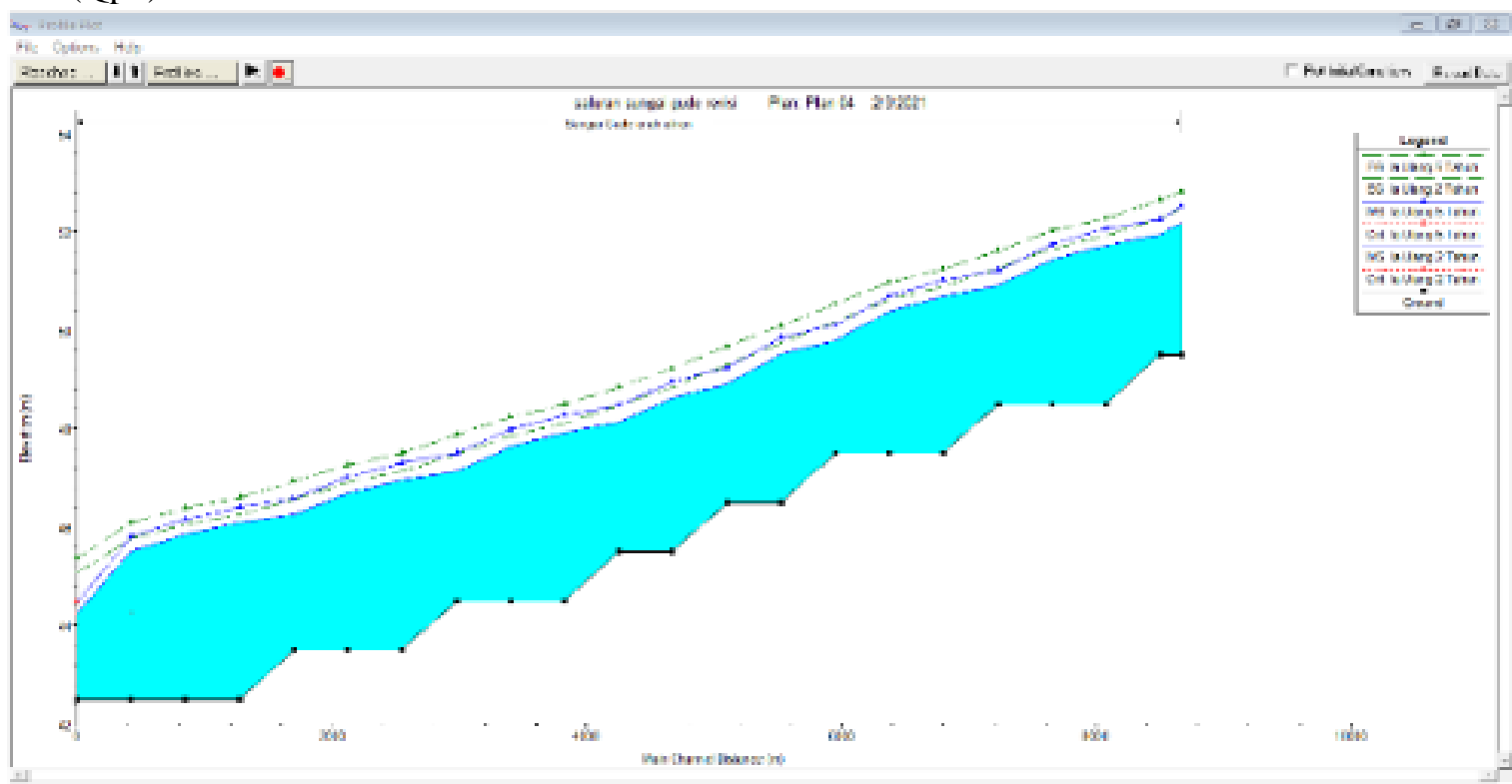

Gambar 6. Plot Profil Memanjang Sungai pada Debit Rencana Periode Ulang 2 Tahun dan 5 Tahun

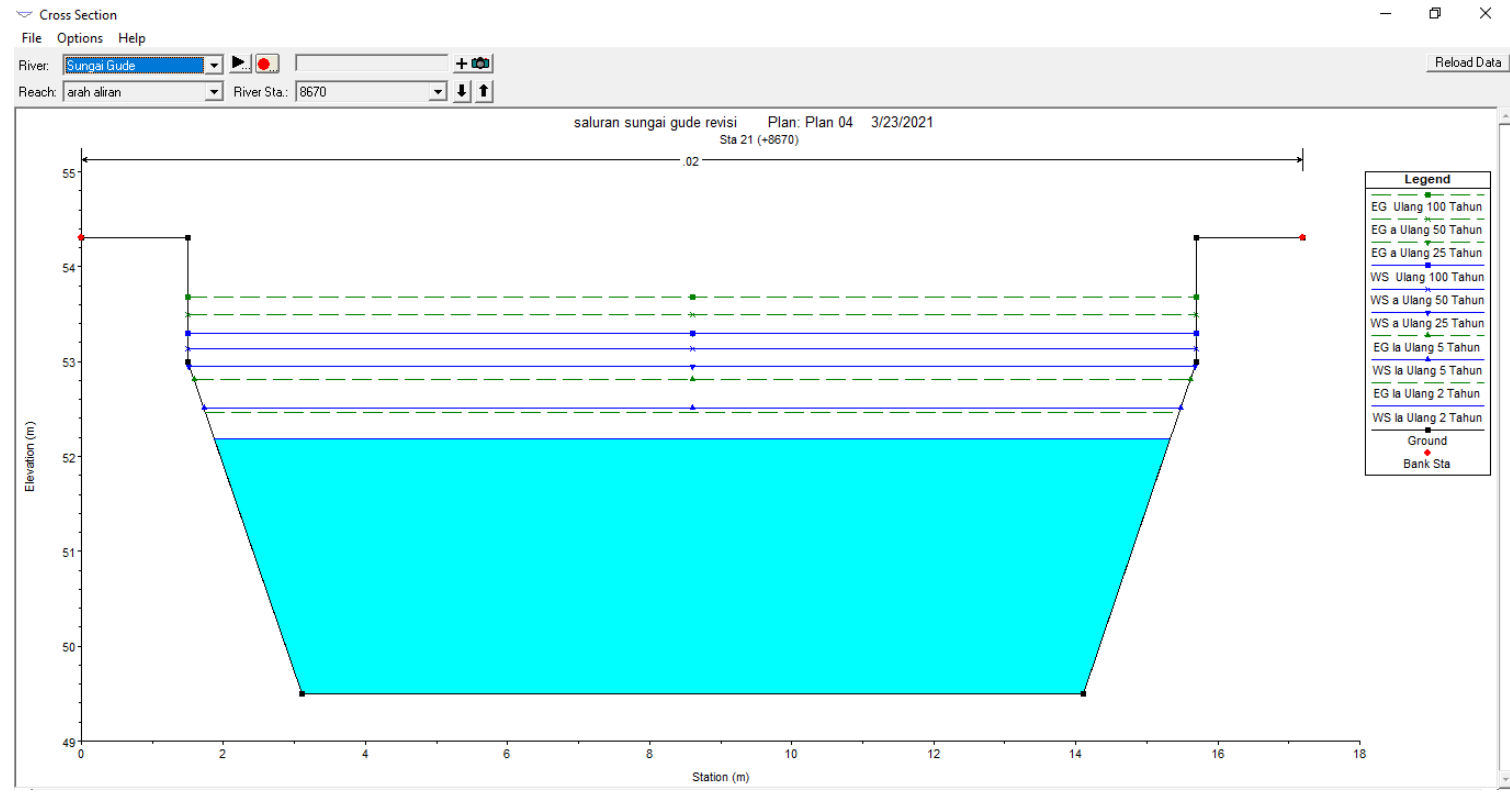

Gambar 7. Plot Profil Melintang pada Debit Rencana Periode Ulang 2 Tahun dan 5 Tahun

Berdasarkan hasil perhitungan redesign penampang, diketahui kapasitas redesign penampang sungai dapat menampung debit pada periode ulang 2 tahun dan 5 tahun dan ditunjukkan pada Gambar 6 dan Gambar 7. Terlihat pada Gambar 7 jarak antara muka air dengan permukaan tanggul setinggi 1,2 meter pada debit rencana periode ulang 2 tahun dan jarak antara muka air dengan permukaan tanggul setinggi 1 meter pada debit rencana periode ulang 5 tahun.

\section{Kesimpulan}

Berdasarkan hasil perhitungan debit banjir dengan kala ulang 2 tahun dengan nilai $76.89 \mathrm{~m}^{3} / \mathrm{dtk}$,

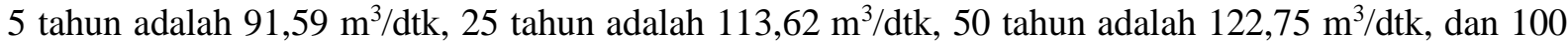
tahun adalah 131,80 $\mathrm{m}^{3} / \mathrm{dtk}$. Kapasitas tampung existing Sungai Gude tidak mampu menerima debit rencana tersebut. 
Solusi untuk menanggulangi masalah kapasitas tampung yaitu dengan normalisasi sungai terutama untuk debit rencana kala ulang 2 tahun dan 5 tahun. Normalisasi dilakukan dengan pengerukan sedalam 1,5 meter dari kondisi eksisting sehingga kedalaman sungai menjadi 3,5 meter serta dengan dibuatkan tanggul pada kedua sisi sungai dengan ketinggian 1,3 meter yang mengacu pada perhitungan tinggi jagaan. Normalisasi dan penambahan tanggul dilakukan pada sepanjang sungai dari Sta 0 - Sta 21.

\section{Referensi}

[1] M. F. G. Fajar and A. Sudradjat, "Analisis Kondisi Eksisting Penampang Sungai Cisangkuy Hilir Menggunakan Hec-Ras 4.1.0," vol. 18, no. April, pp. 43-53, 2012.

[2] M. Z. Hanie, A. Perwira, M. Tarigan, and H. Khair, "Analisis Mitigasi Banjir di Daerah Aliran Sungai BaburaBerbasis Sistem Informasi Geografis (SIG)," 2017.

[3] LKPLHD, "Informasi Kinerja Pengelolaan Lingkungan Hidup Daerah Kabupaten Jombang Tahun 2016," no. 137, 2016.

[4] F. I. Atmoko and D. A. D. Nusantara, "Analisis Kondisi Existing Sungai Gude PlosoMenggunakan HEC-RAS Versi 5.0.7,” pp. 1-9, 2020.

[5] E. E. Budianto, "Dua Desa di Jombang Diterjang Banjir," detikNews, Jombang, 2019.

[6] E. Q. Ajr and F. Dwirani, "Menentukan stasiun hujan dan curah hujan dengan metode polygon thiessen daerah kabupaten lebak," J. Lingkung. dan Sipil, vol. 2, no. 2, pp. 139-146, 2019.

[7] N. Aritonang, Bahan Ajar Hidrologi Teknik. Surabaya: Universitas Negeri Surabaya, 2013.

[8] I. Ramehiang and J. Rombang, "Anailisi Koefisien Aliran Permukaan pada Tiga TipeLahan di Tanah Andisol," 2019. 